\title{
- LÚDICO EM SALA DE AULA DE LINGUA ESTRANGEIRA E UM BREVE OLHAR PARA A LITERATURA
}

Mariana Furst VIZA'

RESUMO: O objetivo deste artigo é mostrar o papel do lúdico na sala de aula de língua estrangeira. Para isso, traçamos um percurso histórico e teórico de sua utilização na aprendizagem do Francês Língua Estrangeira (FLE). Ao final de nossa reflexão, propomos a utilização de atividades lúdicas também no campo da literatura e fornecemos dois exemplos de experiências nesse sentido.

PALAVRAS-CHAVE: lúdico, sala de aula, FLE, literatura.

RESUMÉ: L'objectif de cet article est de montrer le rôle du ludique en classe de langue. Pour cela nous faisons un parcours historique et théorique de son utilisation dans l'apprentissage du Français Langue Étrangère (FLE). A la fin de notre réflexion nous proposons l'utilisation des activités ludiques aussi dans le domaine de la littérature et nous donnons deux exemples dans ce sens.

MOTS-CLÉS: ludique, classe de langue, FLE, littérature.
1 Universidade Federal de Minas Gerais (UFMG). É Mestre em Letras pela UFMG. E-mail: marianareis. furst@gmail.com 


\section{Introdução}

Este artigo é resultado de dois trabalhos nossos: um minicurso sobre o lúdico em sala de aula, ministrado em novembro de 2013 para alunos do curso de Letras de todas as licenciaturas da Universidade Federal de Viçosa (UFV), e duas atividades propostas no curso de Literatura 1, ministrado no primeiro semestre de 2013, na mesma instituição, para alunos da licenciatura em francês.

Na Parte I de nosso artigo, discorreremos sobre os três pontos referentes à primeira parte do título anunciado: o lúdico, o lúdico em sala de aula e o lúdico em sala de aula de língua estrangeira. De certo, todo professor sabe que o aprendizado lida com o prazer do ser humano de aprender e descobrir. Porém, quando o ensino se dá em grupo, como é o caso da sala de aula, percebemos tanto as competências diversas quanto a inevitável comparação entre os alunos. Neste sentido, o lúdico pode estimular, desafiar, congregar em torno de uma meta comum e, deste modo, preparar para os fracassos e adversidades. Sendo assim, a utilização de elementos lúdicos pelo professor mostra ao aluno que, se por um lado, o que é realizado em sala é sério e importante, por outro, não tem grandes consequências. Nosso intuito com este trabalho é, portanto, em primeiro lugar, analisar algo que normalmente é desenvolvido intuitivamente pelos mestres.

Deixaremos para a Parte II nosso breve olhar sobre a presença do lúdico no ensino de literatura. Dada a complexidade do assunto, é evidente que não pretendemos esgotá-lo, mas incentivar o exame da questão. Refletiremos sobre a leitura literária e a interpretação de textos, relacionando-as com o tema central deste texto. Nosso objetivo é demonstrar que mesmo a partir de textos considerados difíceis podemos realizar uma aula de literatura que seja agradável, produtiva e divertida, assim como ocorre nas aulas de língua estrangeira, diante de temas gramaticais não facilmente assimiláveis.

É sabido que, na maioria das universidades brasileiras, apesar da especialidade do professor de Letras, este transita entre o ensino de língua e literatura. Assim sendo, se por um lado temos de lidar com as limitações do nosso sistema de ensino, por outro, o trânsito entre os dois campos acaba nos dando a oportunidade de refletirmos a respeito de ambos e de cotejarmos as suas práticas. É neste sentido que este trabalho se escreve. 


\section{Parte I}

\section{O lúdico no ensino}

Se buscarmos a definição de lúdico no Novo Dicionário Aurélio da Língua Portuguesa, teremos: "referente a, ou que tem caráter de jogos, brinquedos e divertimento: a atividade lúdica das crianças". Além do adjetivo que há muito se tornou nome (pois deixamos facilmente a palavra "ludicidade" para falar do "lúdico"), podemos observar que a definição não contempla explicitamente a esfera do prazer e da imaginação, e a diversão se restringe tão somente ao mundo das crianças.

Mesmo quando pensamos na utilização do lúdico como recurso pedagógico ele parece de fato se limitar ao universo infantil. Adolescentes e adultos costumam olhar para as atividades lúdicas com certo descrédito. $\mathrm{O}$ divertimento considerado legítimo na infância é visto como o oposto do que é sério e aceitável para a idade adulta. Podemos atribuir essa desconfiança à falta de critério e reflexão de alguns professores no que concerne ao uso do lúdico nas salas de aula de ensino fundamental e médio e/ou a vivências pessoais dos alunos, que se sentem tolhidos, pressionados ou intimidados com os conteúdos.

Filmes dados como tapa-buracos para preencher vazios e músicas ou jogos colocados para completar uma aula que não foi bem planejada são alguns exemplos de descaso com a atividade. Somadas ao pouco cuidado na prática do lúdico, essas estratégias propõem ainda um tipo de aula não convencional, de difícil aceitação por parte de alguns alunos. É preciso ressaltar, com efeito, que algumas práticas que infantilizam os alunos podem fazê-los se sentir desconfortáveis e envergonhados. A diferença entre uma atividade lúdica e um jogo é que este tende a ser mais competitivo, gerando uma situação à qual nem todos reagem bem. Porém, se não há um vencedor e se todos respondem, ninguém se envergonha de participar.

Contudo, quando o assunto é língua estrangeira, o quadro muda bastante. A utilização do lúdico torna-se quase imperativa, a fim de tornar as aulas mais agradáveis e quebrar resistências e temores. De acordo com Haydée Silva (2005), referência no estudo do jogo como instrumento pedagógico, há uma idealização crescente do jogo no Ocidente, sendo este exaltado como princípio base da educação. A estudiosa identifica certa relutância persistente por parte de adolescentes e adultos quanto ao jogo em sala de aula de língua estrangeira, todavia afirma que isso se dá apenas pela distância entre a quantidade 
de práticas e a pouca teorização acerca do assunto, e também pelo pouco rigor na utilização dos jogos.

Nos textos acadêmicos a respeito do tema, alguns deles relatos de estágio de mestrados profissionalizantes, e nos sites que oferecem uma grande quantidade de material - além de nos transportar para outras páginas e blogs igualmente úteis - percebemos que a diversidade de atividades abarca tanto as diferentes faixas etárias quantos os diversos níveis de língua. Em termos de língua estrangeira o lúdico não se circunscreve às crianças nem tampouco aos iniciantes.

Quanto ao melhor momento para as atividades lúdicas em sala, os pesquisadores parecem unânimes em dizer que elas podem ser usadas no início, no meio e no fim do curso. Elas são úteis tanto para retomar o assunto da aula anterior, quanto para fazer a passagem de um assunto para outro ou mesmo reforçar determinado conteúdo na conclusão do curso. Além de ser utilizado como reforço, o lúdico é útil também para atender a uma determinada necessidade da classe, para estimular o grupo ao aprendizado de um novo conteúdo ou simplesmente para criar um momento de prazer e relaxamento na sala. Quando há um desânimo geral da classe em certo momento do curso, por vezes em função de um tema particularmente complexo, isso pode servir para criar um ambiente agradável sem tirar o aluno do contato com a língua estrangeira.

Para todos esses momentos, o modo de lidar com o lúdico não varia. De acordo com Silva (2005), é necessário que o professor trabalhe com rigor e consciência. A atividade lúdica não é desprovida de seriedade; deste modo, há que se conhecer o material a ser trabalhado. No caso do jogo de tabuleiro, por exemplo, exige-se o domínio das regras, do funcionamento do jogo, do tempo aproximado da partida. Para a estudiosa, não é o material lúdico em si que é eficiente, mas a utilização que fazemos dele. O professor precisa analisar se a atividade proposta é adequada para o nível de língua que está lecionando, para a faixa etária dos alunos. Ele precisa, ainda, levar em consideração o espaço físico de que dispõe e o tempo de aula que poderá gastar com a atividade. Analisar o nível socioeconômico e cultural da turma o ajudará também a verificar a eficácia de determinada atividade em detrimento de outra antes mesmo de executá-la.

Silva (2005) pontua duas posturas essenciais a adotar na utilização do jogo em sala de aula. A primeira é enxergá-lo como uma ferramenta. Utilizar atividades lúdicas não é sinônimo de êxito garantido, pois o jogo não tem propriedades miraculosas. A segunda postura é a do professor como ator, e não como mero executante. É necessário 
que ele acredite na atividade e se envolva com ela para que o aluno sinta-se à vontade para fazer o mesmo.

Diante do que foi dito, pode-se perguntar, contudo, o porquê da utilização deste tipo de material em sala de aula. Dentre as vantagens, destacamos, a partir de Amaral (2011), Houstiou (2010) e de nossas próprias reflexões alguns pontos. Primeiramente, o aluno torna-se responsável pelo seu aprendizado. Em muitas atividades, ele é convidado a deduzir um conceito gramatical ou adquirir um vocabulário sem a prévia intervenção do professor. Além disso, o aprendizado se dá de modo descontraído. Em uma sala de língua não temos apenas alunos com facilidades ou que aprendem por prazer. A leveza no aprendizado ajuda tanto os que têm maiores dificuldades quanto os que não gostam da língua. Trata-se, ainda, de um modo de testar se o aluno aprendeu de fato. Muitas vezes, após a exposição do conteúdo, o aluno tem dificuldade de expor a sua dúvida ou de dizer que tem dificuldades. No momento da atividade lúdica ele é testado no que realmente aprendeu. O elemento lúdico facilita o trabalho em turmas heterogêneas. Como as atividades são variadas há a possibilidade de trabalharmos as múltiplas inteligências. Outro benefício do trabalho com o lúdico é que ele ajuda a corrigir erros recorrentes. Os erros vêm à tona no momento da atividade e são mais fáceis de serem corrigidos. Muitas vezes o próprio aluno percebe onde errou; quando não, fazemno os colegas que estão jogando com ele.

O lúdico tem a vantagem de auxiliar na associação de ideias. $\mathrm{O}$ estudante que tem dificuldade para lembrar diretamente do conteúdo acaba se lembrando da atividade que realizou no aprendizado deste. Além disso, ele favorece a interação entre os alunos. Um dos grandes benefícios para uma aula de língua estrangeira é uma classe participativa e colaborativa. Mesmo as atividades competitivas podem criar um clima amistoso, se bem conduzidas. Outro benefício da atividade lúdica é que ela permite lidar com situações autênticas, pois ajuda na simulação das situações reais do cotidiano. Além disso, um aspecto interessante deste tipo de atividade é que ela trabalha valores como ganhar e perder. Por meio da experiência lúdica a pessoa toma distância do fracasso e pode lidar mais facilmente com suas dificuldades, não apenas linguísticas, mas também pessoais e relacionais. Por ser um modo de evasão, a atividade permite que o aluno se desconecte por alguns momentos do ambiente social que o cerca e aprenda sem se dar conta de que o faz, pois sua atenção está mais centrada na experiência lúdica do que no conhecimento a ser adquirido. De um ponto de vista cognitivo, a atividade oferece também vantagens na medida em que reforça o trabalho de classificação, ordenação, lógica, dentre outros. 
O lúdico favorece, ainda, uma maior participação dos alunos, fazendo com que a atenção deles não esteja focada exclusivamente no professor. Por fim, sabe-se que o objetivo geral do ensino é dar autonomia e independência ao aluno por meio de recursos que fomentem sua criatividade, sua habilidade e destreza em tarefas diversas.

Tendo levantado os pontos favoráveis, faz-se necessário mencionarmos possíveis dificuldades na utilização do lúdico em sala de aula, para as quais apresentamos algumas soluções. Primeiramente, algumas atividades podem deixar os alunos entusiasmados e exaltados, gerando ruídos que vão além da sala de aula, podendo causar algum desconforto. Um modo de lidar com este problema é prevenir os professores das classes vizinhas, a fim de evitar constrangimentos e desacordos. Outro problema frequente é o tempo do professor, tanto para a elaboração e confecção do material lúdico quanto para a execução da atividade em classe. Um modo de contornar a situação é lembrar que o material que demanda esforço e tempo, depois de pronto, é utilizável por incontáveis vezes. Em relação ao tempo em classe, é preciso que o professor, além de refletir com antecedência na atividade, esteja ciente de que o lúdico não é um momento à parte no curso, mas uma ferramenta para o ensino. Não se trata de um suplemento, mas de um substituto para práticas tradicionais. Deste modo, não há perda de tempo ou tempo gasto em excesso, pois um conteúdo bem compreendido no momento da atividade não exige do professor que retorne ao mesmo ponto por diversas vezes. $\mathrm{O}$ uso da língua materna pode ser também um obstáculo. No momento da atividade lúdica é possível que o aluno, ao se envolver nela, esqueça por vezes de utilizar a língua estrangeira. Em alguns casos, pode sentir-se constrangido em comunicar na língua alvo ou exposto. É necessário dosar o uso da língua materna em classe: impedi-la totalmente pode inibir o aprendiz, assim como aceitá-la a todo instante impede-o do contato com o estrangeiro, o diferente. É preciso que o professor saiba lidar com a diversidade dos alunos a seu favor. Se por um lado as múltiplas inteligências são uma vantagem, a diversidade pode ser empecilho, já que nem todos vão receber a atividade da mesma forma e alguns podem nem sequer aceitá-la. O modo de resolver esta situação é fornecer uma ampla gama de atividades, a fim de que em algum momento o aluno que é indiferente sinta-se motivado a participar.

Conectar o aluno à infância e possibilitar que ele recupere boas lembranças ou reformule as que foram ruins pode fazer com que ele se mova em dado momento, tanto no sentido concreto como metafórico. Possibilitar que cada um faça sua caixa de papel e fale sobre as lembranças contidas nela, baseando-se para isso no episódio do filme $O$ fabuloso 
destino de Amélie Poulain ${ }^{2}$, como sugere o site leszexpertsfle.com, pode ser mais que um exercício sobre a utilização de verbos no passado. Jogos conhecidos como cabra-cega e coelho-sai-da-toca podem ser readaptados neste mesmo sentido. Em termos de condições materiais, o jogo pode representar um investimento financeiro inviável para o professor. Quanto a isso, é importante que o professor saiba criar suas atividades a partir dos meios dos quais dispõe. A criação do material lúdico depende, sobretudo, da imaginação e criatividade de quem o concebe. Nesse sentido, é importante que o professor partilhe tanto as experiências lúdicas quanto o material criado com os colegas de profissão, com o intuito de aperfeiçoar cada vez mais as suas atividades e ampliar o leque de opções.

Percebe-se, pelo que foi dito acima, não apenas que as vantagens suplantam as desvantagens, mas também que há modos de se lidar com as dificuldades que o lúdico apresenta. Portanto, fica evidente o interesse de empregá-lo como ferramenta para o ensino de línguas. Prosseguimos, assim, nossa reflexão, partindo para o segundo ponto do título deste texto: o lugar do lúdico, a sala de aula.

\section{O lúdico e a sala de aula}

Não, o lúdico nem sempre teve um lugar garantido na sala de aula. Da Antiguidade ao século XVIII, o jogo era definido pela sua negativa. Ele era o não sério, o não real, o não útil, o não trabalho. $\mathrm{O}$ jogo estava relacionado com a criança, que não era considerada como um indivíduo pensante nessa época; ao adulto restavam os jogos de azar. Porém, o jogo é uma necessidade humana e sempre existiu. O que ocorre é que nem sempre o ensino se serviu dele de forma consistente, sistemática e formal.

Na Renascença o jogo passa a ser utilizado na educação dos príncipes, para o aprendizado do latim. Os jogos de memorização antecedem os atuais jogos de papéis. Contudo, é apenas no Romantismo que o lúdico passa a ser visto de forma positiva. Com os estudos sobre origem e natureza, os olhares se voltam para a criança, que passa a ser considerada representante do ideal de pureza. Ela estaria livre das influências da sociedade, pois ainda não teria sido corrompida por ela. Como as atividades lúdicas visavam o pleno desenvolvimento infantil, as crianças passam a ser vistas como paradigmas do humano em formação, moldável e passível de aprimoramento pelo aprendizado.

Hoje o lúdico é ao mesmo tempo desvalorizado e supervalorizado, de acordo com a visão que se adota: a antiga ou a romântica. De
2 Le fabuleux destin d'Amélie Poulain, França, 2001, a cores. 
acordo com Jany Pereira (2005:97), a sociedade moderna, seguindo a primeira delas, opõe o lúdico ao trabalho. Os momentos distantes do trabalho são considerados improdutivos e servem apenas para que o trabalhador esteja pronto para trabalhar novamente. Brincar não é visto como algo produtivo. Os playgrounds reforçam esta ideia ao criar um lugar de brincadeira separado do lugar de trabalho. É preciso esclarecer, entretanto, a diferença entre teoria e prática, já que hoje existem propostas pedagógicas baseadas no lúdico, como é o exemplo da Escola da Serra, em Belo Horizonte. Segundo a autora, um aspecto que reforça a visão separatista é o da hierarquização. O professor tem dificuldade de abrir mão do papel social que ocupa para se tornar simplesmente sujeito da brincadeira, temendo que o aluno confunda a sua atuação e ele perca o lugar que ocupa na sala de aula, o que supostamente geraria uma "quebra de autoridade". Essa afirmação, entretanto, parece distante da nossa realidade brasileira, na qual os professores nem sempre conseguem se impor, o que revela uma crise de autoridade.

Apesar do que foi dito, não nos parece que seja difícil para o aluno entender a distinção existente entre ele e o professor, mesmo que ele não a aceite inteiramente. Na maioria das escolas e universidades, que ainda adotam uma postura bem tradicional de ensino, a posição que o professor ocupa na sala de aula é diferenciada. Enquanto os alunos estão assentados, ele normalmente está de pé. Além disso, é ele quem seleciona o conteúdo, as atividades, elabora as provas, escolhe as brincadeiras e o momento para elas; é ele quem distribui os pontos e pontua. Deste modo, é claro para o aluno o lugar que o professor ocupa na sala de aula. A abertura para a experiência lúdica em sala de aula por parte do professor revela-se na disposição para o diálogo, na cumplicidade no momento do jogo, no aprendizado em conjunto.

Na aula de língua estrangeira este não foi sempre o lugar do professor em sala de aula. De igual maneira, não foi desde o início da aprendizagem do FLE que a atividade lúdica esteve presente neste espaço, como mencionamos no início desta seção. A utilização do lúdico passa de uma completa ausência para uma quase onipresença nos cursos de língua estrangeira: para todos os níveis de língua e faixas etárias. Seja por professores iniciantes ou experientes, as atividades lúdicas são hoje utilizadas amplamente em sala de aula.

\section{O lúdico e a língua estrangeira}

A abordagem comunicativa da língua, que dá início às discussões sobre o lúdico, tem início na década de 70. O contexto políti- 
co-econômico em que ela nasce é o da expansão do Mercado Comum Europeu, no qual a necessidade de comunicação entre os povos é uma realidade. Há dois fatores, principalmente, que caracterizam a nova abordagem: o professor não é mais visto como centro do saber, mas como facilitador no processo de aprendizagem. Por sua vez, o aluno não é considerado como receptor, mas agente deste processo; além disso, a utilização de materiais autênticos ganha espaço nas salas de aula. Nos anos 80, inicia-se uma real reflexão em torno do lúdico, graças à integração dos jogos de papéis em sala de aula. Também na década de 90 os jogos de palavras, letras e tabuleiros ganham terreno. Hoje as formações em torno da temática do jogo se multiplicam e a experiência lúdica é fortemente recomendada nos textos pedagógicos.

Pontuamos, na primeira parte deste texto, as atividades que consideramos lúdicas no contexto da sala de aula. Gostaríamos, todavia, de elencar, dentro da lista citada, alguns materiais que tínhamos em mente. São eles: excertos de jornais, revistas, literatura, Bandes Déssinées (para um trabalho com texto); apresentações em Powerpoint, recortes, desenhos, pinturas, publicidades (para um trabalho com imagens); filmes, videoclips, animações, curtas-metragens, sketchs, publicidades, jornais televisionados, documentários (para um trabalho com imagens); transmissões de rádio, canções, gravações diversas (para um trabalho com áudio); jogo de tabuleiro, memória, bingo (para um trabalho com jogos); caixas, bonecos, bolas, garrafas (para um trabalho com objetos); enigmas, provérbios, adivinhações, forcas, adedanhas (para um trabalho com o vocabulário).

Haydée Silva (2005) esclarece a importância de quatro aspectos para a utilização do lúdico em sala de aula. O primeiro deles é o material lúdico. Este deve ser atraente, para, por um lado, despertar a curiosidade do aluno e, por outro, lhe permitir manipulá-lo. O segundo aspecto é a estrutura lúdica, que diz respeito ao total domínio do jogo por parte do professor e ao cumprimento das regras estabelecidas durante a sua execução. O contexto lúdico, terceiro aspecto trabalhado pela pesquisadora, contribui para o bom andamento da atividade lúdica na medida em que o professor preocupa-se em instalar um ambiente favorável e em despertar o interesse dos alunos. O professor geralmente conhece seus alunos, portanto é importante que coloque em prática atividades que tenham a ver com o grupo com o qual trabalha, a fim de não constranger ou embaraçar ninguém. O chamado ao lúdico não deve ser feito, contudo, apenas no momento da atividade; a maneira de organizar a sala e de compô-la criativamente é de igual modo importante. 
Para os três primeiros pontos é possível e necessário um controle por parte do professor. Já o quarto aspecto, a atitude lúdica, não é passível de controle. Trata-se do envolver-se pessoalmente com a atividade proposta, o que depende da disposição subjetiva de cada aluno. Um fator a ressaltar, todavia, é que, se o próprio professor não se sente motivado a realizar uma atividade, dificilmente ele despertará o interesse de seus alunos para ela.

Além do material, da estrutura, do contexto e da atitude lúdica que favorecerão a utilização das atividades em sala de aula, outro aspecto relevante é ensinar ao aluno o vocabulário básico para que ele interaja com os colegas e o professor. No caso de jogos, por exemplo, é necessário que ele aprenda como se diz "dado", “carta”, "tabuleiro”, "de quem é a vez", "você está roubando"; para trabalhar música, palavras como "estrofe", "refrão", "melodia", "letra” são úteis; e assim por diante, com outros meios, tais como poemas e filmes.

Antes da elaboração da atividade é necessário que o professor tenha em mente as necessidades de seus alunos e saiba que objetivos pretende alcançar com ela. De acordo com Coralie Houstiou (2010), ele precisa partir do nível de seus alunos e definir quais competências vai tratar (gramática, vocabulário, fonética etc.), por meio de quais atividades linguísticas (compreensão ou expressão oral e escrita), com vistas a desenvolver quais habilidades (saber contar uma história, pedir uma informação, se apresentar, argumentar etc.) e dentro de qual contexto cultural. Depois disso, ele precisará definir o dispositivo da atividade (o número de jogadores, se será em equipes, a duração da atividade, o objetivo dela), as regras a serem seguidas, bem como o material a ser utilizado (em alguns casos a ser fabricado).

Houstiou (2010) propõe que o lúdico permeie toda a atividade, tanto o momento de escolha das equipes quanto a contagem dos pontos e as possíveis prendas. Para a escolha das equipes, ela sugere que o professor recorra a diversas estratégias: tirar pelos números do dado, se basear nos meses de nascimento dos participantes, utilizar cores (os azuis de um lado e os vermelhos de outro). Para a contagem dos pontos, a estudiosa propõe que o professor dê ao aluno um botão, um grão de milho, enfim, que o recompense com algo pequeno, mas atrativo a cada resposta correta.

Finalmente, ela recomenda o cumprimento de algumas prendas pela equipe vencida, a fim de dinamizar as atividades. Contudo, ressalta que estas devem ser divertidas e, para tanto, sugere algumas, como falar trava-línguas ou cantar uma canção. A atividade lúdica requer do professor um grande investimento fora de sala (da análise à 
feitura da atividade) e também dentro dela (no sentido de criar um clima propício para que ela aconteça, ainda que ele não seja o centro da atenção).

\section{Parte II}

\section{O lúdico e a literatura}

Há algum tempo flertamos com a possibilidade de unir o lúdico e a literatura e, por isso, não gostaríamos de finalizar este texto sem uma breve reflexão a respeito. Nosso intuito não é o de defender o uso da literatura nas aulas de língua ou a possibilidade do aprendizado da língua na aula de literatura. Apesar de ambas as práticas serem legítimas, parece-nos que a literatura, nos dois casos, está a serviço da língua. Sendo assim, não se levaria em conta, antes de tudo, a literatura por ela mesma.

Frank Gonçalves, ao falar sobre a presença da literatura nos livros didáticos de língua francesa dirá:

Ainda que os textos literários nos forneçam um material linguageiro que nos permita refletir sobre a linguagem - parole no sentido Saussuriano - é importante não perder de vista que se trata igualmente de uma produção artística. Parece-nos apropriado concluir que o fato de apreciar a dimensão artística da literatura tem impactos consideráveis na elaboração de uma sequência pedagógica. $(2013: 125)$

O autor acima citado revela a necessidade de evidenciarmos o aspecto estético da obra literária. Além do aspecto linguístico, outro ponto que geralmente ganha destaque no trabalho com a literatura é o cultural. Já nos primórdios do ensino da língua, a literatura era utilizada como recurso didático para aquisição linguística, mas também como forma de ascensão a uma cultura de prestígio. Considerando apenas o âmbito cultural, percebe-se mais uma vez que a literatura não é tratada dentro de seus próprios parâmetros, antes, é igualada a outros textos, como afirma Ana Cristina dos Santos:

Cabe destacar que não discordamos do valor cultural do texto literário. Contudo, se consideramos que todo e qualquer texto se produz dentro de uma cultura específica e 
adquire os sentidos da cultura em que foi produzido, pois quem usa a linguagem, o faz de algum lugar determinado social e historicamente; então, todo e qualquer texto é instrumento para o ensino de questões culturais e não somente o literário. Assim, para tal prática, quaisquer outros textos servirão e não, especificamente, um texto literário. (2008:2290)

Diante da necessidade de abordar o texto literário dentro das suas especificidades, distanciando-o de uma função apenas linguística ou cultural, é que gostaríamos de pensar a aula de literatura. Assim, encaramos o fato de que principalmente no contexto das universidades brasileiras as duas disciplinas, língua e literatura, encontram-se separadas. Mesmo nos concursos públicos para professor de francês é clara a divisão, ainda que dentro da universidade apregoemos a união necessária entre elas.

Santos, ao verificar a não utilização da literatura pelos professores de língua, atribui a dificuldade dos mestres à separação mencionada:

Esses professores reportaram que não utilizavam o discurso literário por considerá-lo uma modalidade complexa, elaborada e de pouca incidência nos usos mais frequentes do sistema da língua, sendo assim, não encontravam espaço para o seu uso em sala de aula. Além do mais, (...) em sua graduação, as disciplinas de língua e literatura eram ensinadas em separado e, por isso, não sabiam como inserir um texto literário nas aulas de língua. (2008:2288)

Apesar da abordagem da autora ser diferente da que propomos, a cisão é clara. Para a proposta de um trabalho com a literatura em língua estrangeira recorre-se geralmente às reflexões realizadas no âmbito da leitura literária em língua materna. Nesse sentido, o trabalho de Inara Gomes é esclarecedor. Ao enfatizar a necessidade de ensinar o aluno a "ler literatura" em vez de "saber literatura", ela se atém ao contexto específico do Brasil.

Para o caso brasileiro, essa observação é tanto mais pertinente quando se conhece a precária formação literária dos alunos dos cursos de Letras, que chegam à universidade com um reduzido repertório de leituras e com noções muito vagas acerca do texto literário. Múltiplos são os fatores que concorrem para isso, a começar pelos históricos e socioculturais que têm impedido a democratização da leitura 
literária e do acesso aos livros. Ao ingressar no curso, em que a literatura permanece como eixo básico de formação, presente desde o primeiro momento, quando, em geral, são ministradas disciplinas de Teoria da Literatura, os estudantes têm dificuldade de identificação do próprio objeto de estudo, pois não encontram, na sua trajetória escolar de leitores, uma representação consistente de literatura, o que compromete seriamente o processo de transformação, ao longo da formação do licenciando, desse objeto de estudo de certo modo inefável, num primeiro momento, em objeto de ensino de suas práticas docentes. (2010:4-5)

O que se observa a partir da análise sociocultural de Gomes é uma perpetuação, ao final do ciclo estudantil, de uma dificuldade de ensinar literatura, pelo fato de o aluno não ter tido acesso a ela diretamente ao longo da vida estudantil e isso se repetir na sua licenciatura. Segundo a autora, trata-se de uma ausência que tem início no ensino básico e permanece na formação acadêmica. Conforme a pesquisadora, para sanar este problema, caberia a promoção de formações continuadas, após os alunos já terem concluído a graduação.

É consenso que a formação inicial, nos cursos de licenciatura, não tem conseguido reverter as insuficiências leitoras herdadas do ensino básico, sendo necessária a constante oferta de formação continuada. De maneira que, hoje, a formação do profissional de Letras enfrenta o desafio de, superando-se as deficiências da educação literária e leitora em toda trajetória escolar do estudante que chega ao curso, transformá-lo num agente de promoção da leitura. (2010:6)

Essa realidade não é diferente para os alunos de licenciaturas em língua estrangeira: ora adere-se à teorização da literatura, ora à fragmentação. Neste caso, procura-se torná-la mais acessível, quiçá, mais palatável, ao oferecer ao aluno apenas excertos das obras e não leituras completas de livros. E mais uma vez reproduz-se na universidade um modelo que no ensino primário e secundário não surte efeito sobre o aluno.

Nas práticas de leitura escolar, registradas ao longo do tempo, sempre predominaram os fragmentos de textos. A leitura de obras completas, mais árdua e difícil, nunca foi uma prática generalizada. Mesmo em países em que há uma cultura da leitura bem sedimentada, os modelos de leitura literária operados na escola não rompem com esse tipo de prática. (2010:5) 
Além da escolha pelo fragmento, outra constante apontada pela autora é a presença das obras contemporâneas em detrimento das clássicas.

A predominância destes últimos [textos contemporâneos] em detrimento de clássicos nacionais e Universais [nos livros didáticos] não favorece a percepção da literatura como um fenômeno artístico e histórico-cultural que possui uma tradição. (...) Neste quesito, o que se tem observado é uma grande recorrência das mesmas obras e dos mesmos autores e a exclusão de gêneros e de tipos de textos considerados de difícil abordagem didática. (2010:10)

Antes de prosseguirmos nas considerações acerca da leitura, consideramos importante esclarecer que esta segunda parte do texto é um esforço de reflexão que busca trazer para a aula de literatura elementos do lúdico utilizados na aula de língua. Trata-se, portanto, não de aderirmos ao ensino da leitura literária ${ }^{3}$, como é feito nas aulas de língua, de acordo com o que propõe Santos, mas trabalharmos a leitura literária associada à interpretação de textos, nas aulas de literatura. Amor Séoud, em De l'explication de texte à la lecture, fala sobre a separação entre essas duas práticas :

Nous voudrions insister cependant sur un point : la nécessité de bien prendre conscience, avec du recul, que la didactique de la littérature, comme discipline, n’a pu s'établir qu'à partir de cette évolution, c'est-à-dire à partir du moment où la lecture s'est séparée de l'explication de texte, séparation qui a donné lieu à deux épistémès, désormais rivales : celle, d'un côté, de la grande tradition herméneutique, centrée sur l'objet et celle, de l'autre, préconisant une démarche constructiviste, et centrée sur le sujet ; - celle, si l'on veut, qui s'en tient au «texte de l'auteur », contre celle qui promeut le « texte du lecteur », notion qui émerge aujourd'hui dans le milieu des didacticiens, et qui dit à quel point le texte appartient à ce lecteur qui, par sa lecture, y engage son histoire et sa liberté, comme dirait Barthes. $(2009: 67)^{4}$

Segundo o autor, o ensino da leitura foi que propiciou o surgimento da didática da literatura, responsável por refletir sobre o uso da literatura na aula de língua. Contudo, perguntamo-nos se, no contexto da aula de literatura tout court, a conciliação entre as duas práticas não seria possível, como o autor defende. Parece-nos que a diferença entre a aula de literatura e a aula de língua com práticas de leitura
3 A leitura literária trabalha com a concepção de que o leitor é o centro do processo de leitura e não mais o autor ou a obra, fato que deu àquele uma autonomia interpretativa jamais vista. Os principais responsáveis por esta mudança são os representantes da teoria da recepção, Iser e Jauss. $\mathrm{E}$ também o escritor Umberto Eco. Na esteira destes escrevem-se hoje os trabalhos que versam sobre a leitura como uma construção realizada pelo leitor. Dentro dessa abordagem construtivista, acredita-se numa multiplicidade de sentidos na obra literária e não na presença de um sentido único a ser encontrado pelo leitor.

4 Gostaríamos de insistir, no entanto, em um ponto: a necessidade de se tomar consciência, com certa distância, de que a didática da literatura, como disciplina, só pode se estabelecer a partir desta evolução, ou seja, a partir do momento em que a leitura se separou da explicação de texto; separação que deu lugar a duas epistemes agora rivais: de um lado esta, da grande tradição hermenêutica, centrada sobre o objeto; e de outro aquela, preconizando uma abordagem construtivista e centrada no sujeito; a primeira, se preferirem, está ligada ao "texto do autor"; contra aquela, a segunda promove o "texto do leitor”, noção que surge hoje entre os didatas e que diz em que medida o texto pertence ao leitor que, com sua leitura, imprime nele sua história e liberdade, como diria Barthes. (2009:67) Tradução nossa. 
literária é que naquela não se busca criar leitores, mas capacitar um leitor já existente a decifrar e compreender o texto literário. Decerto lidamos com alunos que possuem defasagens no seu ensino, porém, ao se matricularem em uma disciplina literária, ainda que não sejam amantes de literatura, eles possuem alguma disposição para ler.

Porém, temos consciência de que, diferentemente da aula de língua, na aula de literatura o aluno lida com leituras que são obrigatórias e, na maioria das vezes, de difícil compreensão. Os clássicos que deixaram a sala de língua encontram lugar na aula de literatura. Contudo, não se deve perder de vista que, mais do que fornecer os instrumentos necessários para a decifração, uma aula pode ser atrativa e prazerosa . Que o contato com os clássicos, sempre presentes nos programas dos cursos de Letras, não seja um fardo insuportável. Afinal de contas, a cultura francesa é fundada neste legado (o que não ocorre tão fortemente no Brasil, já que nossa base é mais oral que literária). Os "autores inevitáveis" vêm há séculos conformando a identidade francesa. Portanto, ainda que o aluno focalize sua formação na tradução ou em trabalhos bem práticos com a língua não pode fugir dessa herança histórica. Nosso intuito com este texto é, portanto, unir hermenêutica (ou interpretação) e leitura. Se a interpretação é como um jogo - que possui regras, princípios e objetivos - e por meio dela tentamos encontrar no texto cada vez mais pontos que possam referendar uma ideia, a leitura é o lúdico, espaço de liberdade, identificação e criação.

Reconhecemos as diferenças entre as duas práticas, como, por exemplo, o foco no leitor. No primeiro caso, trata-se de responder a um comando externo, ainda que não se tenha tanta empatia pela obra; já no segundo, o professor se limita a apresentar obras de acordo com a capacidade ou interesse do aluno. Contudo, gostaríamos de ressaltar também as semelhanças: os múltiplos sentidos. É preciso ter em mente que, se na leitura literária não há um sentido único, a interpretação também é aberta e infinita. Decerto que, na primeira, não se está preocupado com os rastros do texto que possibilitam a leitura, mas com os efeitos do texto sobre o leitor. Todavia, no trabalho de interpretação é possível conciliar impacto sobre o leitor e verificabilidade textual, o que consideramos um ganho duplo.

Assim, se a primeira prática é como um namoro, uma brincadeira, a segunda é um teste, um trabalho de detetive. Nota-se que a leitura vem crescendo com a internet, aplicativos para celular, redes sociais, mensagens instantâneas, Twitter. Porém, ainda é difícil compreender um texto, seja ele um documento ou um poema. Extrair in- 
formações e deduzi-las é algo que pode e deve ser aprendido. O que se faz no trabalho de interpretação é fornecer ferramentas para o leitor aproveitar ao máximo o que lê: o nome dos personagens é significativo? O uso do espaço ou do tempo? Há ambiguidade? O que é memorável no texto, da forma ao conteúdo? Ele remete a outros livros, tem imagens? Sobre a vida do autor, algo ajuda a entender? E sobre o contexto da época? Porém, nada disso precisa ser feito de forma maçante e sem relação com o universo do aluno.

Tendo em mente essa reflexão retornamos ao objetivo deste texto. Nossa questão é: pode o lúdico, utilizado para o aprendizado da língua estrangeira, ser útil como ferramenta na aprendizagem da literatura? Acreditamos que sim. Parece-nos que, para isso, ele deve adentrar a dinâmica da compreensão e produção escritas, daí a nossa reflexão sobre a leitura literária, que será seguida, a partir de então, pela da produção.

Cristina Pietraróia (2001) propõe, por exemplo, alguns exercícios de preparação para o texto a ser lido, tais como apresentar aos alunos os personagens principais da história e o contexto no qual aparecem e deixá-los imaginar a intriga. Depois, comparar as versões feitas com a narração original. Seguidamente à leitura do texto, a autora sugere trabalhar também sobre os elementos de progressão do mesmo e o modo como se construiu a história. Outra ideia é a utilização de jogos com o léxico do texto, a fim de evidenciar a materialidade da palavra.

Amor Séoud (1997) sugere, como atividade de pós-leitura, a escrita de paródias, a feitura de exercícios de supressão e expansão do texto, a escrita de uma narrativa sem que um fim seja ambicionado, a escrita de textos sobre temas insólitos, de uma página perdida de uma história ou de uma história na contramão da realidade. Estas nos parecem atividades centradas sobre a literatura e não sobre um ponto de gramática ou sobre a necessidade de aquisição de uma lista específica de vocabulário. O texto é o foco e não o meio. Tem-se em mãos o material literário, com todas as suas dificuldades e especificidades; cabe ao professor ensinar o aluno a se apropriar desse material de forma prazerosa e divertida.

\section{Uma experiência com o lúdico na aula de literatura}

Com intuito de realizar algo neste sentido, propusemos a uma turma de cinco alunos da licenciatura em francês, participantes da dis- 
ciplina Literatura da Idade Média ao Renascimento, da Universidade Federal de Viçosa, a leitura e a reescrita de alguns textos clássicos. A proposta da disciplina era recobrir de modo panorâmico o painel literário do século XIII ao século XVII. Nada menos que 400 anos! Optamos por fazer um recorte por gênero, não desconsiderando alguns textos tidos como fundamentais. Escolhemos o teatro como nosso fio condutor e percorremos, para tanto, La farce du maitre Pathelin seguida por Le Cid, de Pierre Corneille, Phèdre, de Racine, e Le malade imaginaire, de Molière. Lemos as quatro obras completas e o Elogio à loucura, de Erasmo (em português), para a compreensão do contexto histórico. Além destas, passamos por fragmentos da Chanson de Roland, de Tristan et Iseult, por uma epístola de Boileau e alguns poemas de Ronsard, du Bellay e Labé, que foram importantes, sobretudo, pelas metáforas literárias contidas em seus versos e repetidas nas peças, tal como a do fogo. Em cada texto trabalhamos a análise literária sem deixar de desenhar um painel histórico para os alunos. Utilizamos documentos sonoros e imagens disponíveis na internet, além de recomendarmos alguns filmes referentes a cada época. Assim sendo, optamos por sensibilizar os alunos antes e durante a compreensão dos textos, apesar de nos determos, nesse texto, sobre a atividade de pós-leitura.

Gostaria de mencionar o trabalho realizado com as duas tragédias do século XVII, Le Cid e Phèdre. Vale ressaltar que esses textos são normalmente considerados de difícil acesso, mesmo para os falantes nativos da língua. Há um léxico específico, bem como todo um contexto histórico por trás das obras. Acrescido a estes desafios estava o nível de língua dos alunos: cursavam o terceiro semestre de francês. Assim, a gramática e o vocabulário das obras colocavam alguns problemas. Esses aspectos, contudo, não foram empecilhos para um real envolvimento dos alunos com a temática dos textos e com as atividades sugeridas. Porém, acreditamos que quando os alunos possuem um conhecimento linguístico mais automatizado, como afirma Pietraróia, eles dominam melhor as estratégias descendentes, tendo maior facilidade de fazer inferências e levantar hipóteses.

No caso de Le Cid, propusemos a atividade de expansão do texto. Para que entremos na proposta, segue uma sinopse da obra, correndo o risco de sermos redundantes para muitos leitores: a peça gira em torno do casal romântico Rodrigue e Chimène. Por causa de uma intriga entre os pais de ambos e a consequente morte do pai de Chimène por Rodrigue, a relação torna-se complicada. Rodrigue não pode deixar de vingar seu pai, que sofrera uma afronta do pai de Chimène, pois a questão da honra era algo extremamente importante para a sociedade da época; Chimène, de sua parte, não pode casar com 
o assassino de seu pai, pois precisa pedir vingança, a fim de honrar a sua família. O conflito entre amor e honra permeia a peça. Devido aos conflitos do casal, seus encontros e desencontros, a peça se aproxima das novelas televisivas, o que acaba criando uma identificação com o estudante brasileiro.

Como a peça termina em suspenso, pedimos aos alunos que sugerissem a continuidade da história de amor entre Rodrigue e Chimène, a qual só seria possível após um ano em que ambos ficariam separados um do outro, por resolução do rei; Rodrigue, por causa da guerra; Chimène, por causa do luto pela morte de seu pai. Esclarecemos que, em uma das versões de seu texto, Pierre Corneille sugere o casamento imediato do casal. Porém, devido ao escândalo que causou este súbito enlace de Chimène com Rodrigue, assassino de seu pai, o dramaturgo, na revisão de suas obras, faz suspense sobre o fim da história.

Deixamos cada aluno escolher o gênero de sua preferência para esta atividade. As escolhas foram variadas: estilo jornalístico, drama em versos (como são as peças teatrais da época) e narração. Fato curioso é que em nenhum dos finais propostos Chimène chegava a se casar com seu par romântico, como a primeira versão do autor. Houve a criação de novos triângulos amorosos, o que demonstra certa fidelidade ao estilo das peças. Em um dos finais, por exemplo, um Infante vive uma relação amorosa com a Infanta de Castilha e com Chimène ao mesmo tempo. Assim, Chimène assume o papel antes designado para a Infanta: de sofrer por um amor que não lhe pertence. A diferença é que o Infante também é apaixonado por Chimène, e não pela filha do rei. Chimène foge com ele e Rodrigue acaba se casando com a Infanta de Castilha. Mas o final não favorece a filha de Don Gomès, que acaba sendo abandonada pelo Infante, grávida de gêmeos.

Em outra versão, Rodrigue é quem encontra uma nova mulher. O quiproquó da falsa morte de Rodrigue é repetido pelo rei, mas, desta vez, para omitir que Rodrigue está vivo e tem outra. Não será exatamente uma peripécia, já que, neste caso, o intuito é de fato omitir que Rodrigue não morreu. Porém, não deixa de ser um combinado entre o rei e o seu cavaleiro, algo presente na peça. Chimène, por sua vez, vai buscar a morte, a fim de encontrar seu pai e seu amado. Nesses dois casos, Chimène parece ser o alvo da punição, o que revela uma linha interpretativa crítica por parte dos alunos.

Houve, contudo, outra versão, na qual Rodrigue é trapaceado. Chimène fica grávida de seu próprio pai. Num estilo que retoma as peças gregas antigas, o aluno finaliza a peça com um oráculo: “Un jour 
il y aura un amour/Un amour que personne ne l'a jamais vu/Dessiné entre le ciel et la terre/ Brodé au combat de l'amour et de l'honneur/ La fleur pleure et l'homme lutte/ L'enfant de la fleur est frère de son amour...”. Vale ressaltar a ousadia e o caráter de vanguarda desta produção. A coragem da aluna revela uma aprendiz bastante autônoma e capaz de reler a tradição, de provocar e de criar a partir do que existe. Ela usa com perspicácia rima e métrica, trabalha com modelos e ao mesmo tempo se distancia deles.

Alguns aspectos interessantes no que diz respeito à construção do texto dos alunos são: a retomada do vocabulário da peça (feu, flamme, sang, honneur), do tom da peça (em alguns momentos risíveis ou em momentos sérios contemplados como risíveis), da estrutura gramatical (inversão do sujeito), a mudança entre as formas de tratamento (tu e vous), a criação de máximas (semelhantes à da peça), utilização de imagens poéticas.

Para Phèdre, pedimos aos alunos que imaginassem um tribunal. Cada um seria responsável por defender um personagem da história e consequentemente acusar os outros, apontando, assim, um culpado para a morte de Hippolyte. Segue um resumo da peça, recorrendo na possível repetição para os que a conhecem: Phèdre, segunda esposa de Thésée, rei de Atenas, sente-se atraída por Hippolyte, filho do rei. Em dado momento chega a notícia de que Thésée, seu marido, depois de muito tempo longe de casa, está morto. Phèdre encarrega-se de anunciar à Hippolyte o falecimento do pai ao mesmo tempo em que revela seus sentimentos a ele. Thésée, contudo, não morrera e volta para casa. Phèdre agora se sente desonrada e quer se matar. Oeone, sua ama, não encontra outro meio de salvá-la, a não ser acusando Hippolyte. Escorraçado de casa pelo pai, Hippolyte acaba encontrando a morte em uma fatalidade. Sabedora disso, Phèdre também se mata.

A revelação amorosa seguida de quiproquós é também recorrente em novelas, filmes e seriados. Por ser algo "familiar", os alunos sentiam-se à vontade para julgar um ou outro personagem, apontando o culpado pelo desfecho. Na tentativa de defender o seu cliente, eles exaltavam as virtudes destes e culpavam os outros personagens da história, apresentando, pelo texto, os argumentos. Alguns destes eram inventados. Porém, o mais curioso era a retomada de imagens de textos anteriores, como as que faziam alusões aos cavaleiros, como os da Távola Redonda, sobre os quais muito falamos. No texto do aluno que fez a defesa de Phèdre, temos as seguintes frases: "Hyppolite était un jeune chevalier. Il était très fort et grand. Ses cheveux étaient frisés et noirs comme une belle nuit sombre. Il y a encore des rumeurs qui 
disent que sa beauté était presque de la magie" . Houve, ainda, julgamentos baseados no padrão moral social, como foi o caso da defensora de Hyppolite: "La coupable est Phèdre pour sentir un amour criminel, un amour incestueux".

A atividade demandou dos estudantes um conhecimento da história e a capacidade de argumentar a favor de seu "cliente". A utilização dos conectores, num texto que deveria ser essencialmente argumentativo, foi empregada corretamente e a retomada da história realizada, cumprindo-se, por conseguinte, o objetivo.

Em ambos os trabalhos propostos, os alunos se envolveram com entusiasmo, o que nos fez pensar que uma abordagem diferenciada do objeto literário pode aproximá-los dele, indiferentemente das dificuldades iniciais. Houve quem relatasse até mesmo o surgimento de um gosto antes inexistente pela literatura, algo sem dúvida recompensador para todo professor.

Notamos, entretanto, que nos faltou um tempo maior para trabalhar os textos escritos pelos alunos. No caso do Cid, houve tempo para uma reescrita do texto, a partir de observações no conteúdo e na estrutura. Já no de Phèdre, isso não foi possível. Gostaríamos, ainda, de ter dedicado algumas aulas para que os alunos pudessem ler uns para os outros seus textos. Eles se mostraram curiosos com a produção dos colegas. Acreditamos que teria sido uma troca interessante e uma oportunidade para falarmos mais dos livros, porém, isso também não ocorreu. Fica-nos a tarefa de reservar, em uma próxima vez, um tempo necessário para esse trabalho de troca de experiências entre eles, o que não deixa de ser um modo de trabalhar as outras competências: produção e compreensão oral.

Como os textos dos alunos brincavam com as palavras e com a temática, gostaríamos de finalizar este artigo apontando para um recurso que nos parece unir de maneira interessante o lúdico e a literatura. O trabalho com a paródia, citada por Séoud inclusive, nos parece produtivo, pois lida com a aproximação e o distanciamento do texto. Sem dúvida, trata-se de uma leitura contra o texto, já que a paródia é a criação de um texto paralelo, sendo o sentido original da palavra "canto paralelo". Trata-se de um modo produtivo de se envolver com o texto, porque preza tanto pela proximidade quanto pela distância, se considerarmos que é preciso saber suficientemente bem a respeito de um texto para só então parodiá-lo.

Outro aspecto que favorece a utilização da paródia, sobretudo em terras brasileiras, é a nossa facilidade para o riso. Rimos de situações 
trágicas: a queda de um viaduto em Belo Horizonte, as corrupções políticas, a goleada em uma Copa do Mundo, justamente no ano em que ela é sediada no próprio país. As mídias sociais pululam de piadas, criadas quase instantaneamente. Nas notícias de jornais percebe-se o espanto dos estrangeiros com a nossa alegria, o nosso calor humano, a nossa receptividade. Porém, nós bem sabemos que o nosso riso não é sempre alegre como eles imaginam; é muitas vezes sarcástico e irônico, como é o da paródia. Além dessa nossa característica tão culturalmente arraigada, há outra, anunciada anos atrás por Oswald de Andrade em seu manifesto: a da antropofogia. Trata-se da nossa capacidade de trazer o que é de fora, devorar a cultura estrangeira e fazer dela algo novo. De acordo com Affonso Romano de Sant'Anna, o texto parodístico é "uma nova e diferente maneira de ler o convencional. É um processo de liberação do discurso. É uma tomada de consciência crítica”. (2003:31)

A paródia reescreve, sobretudo, textos clássicos, sendo, portanto, uma ferramenta interessante para o trabalho com essas obras, muitas vezes relegadas ao esquecimento ou tratadas superficialmente, devido ao grau de dificuldade que apresentam. É importante notar que não basta construir um texto de caráter cômico para fazer uma paródia, antes, é preciso conhecer o texto original profundamente, a fim de deslocar o seu sentido. Obras como a Odisseia, a Ilíada e a Eneida já passaram por diversos processos de parodização. O Virgile travesti, de Paul Scarron, e o Homère travesti ou l'Iliade en vers burlesques, de Marivaux, são alguns exemplos. Outro parodista de textos consagrados e até mesmo sagrados é Alfred Jarry. Em La passion considerée comme course de côte, o autor parodia a paixão de Cristo e em Ubu-Roi, seu trabalho mais conhecido, retoma o Édipo Rei, de Sófocles.

\section{Conclusão}

Na Parte I deste texto, vimos que a utilização criteriosa do lúdico em sala de aula promove resultados interessantes no aprendizado da língua estrangeira. Demonstramos as vantagens e desvantagens de se trabalhar com o lúdico e vimos que aquelas suplantam estas.

Diante da boa aceitação por parte de quase todos os alunos e do êxito que o trabalho com o lúdico apresenta, propusemos, na Parte II, uma combinação entre o lúdico e a literatura. De fato, alguns trabalhos nesse sentido têm sido feitos nas aulas de língua estrangeira a partir do viés da leitura. Nosso texto refletiu a um só tempo sobre a leitura literária e a interpretação de textos, buscando aproveitar, nas aulas de literatura, algumas práticas presentes na aula de língua. 
Temos, diante do que foi dito, uma reflexão e algumas propostas. Nossa reflexão procura pensar o porquê de não tratarmos a literatura de forma lúdica no ensino universitário. No início deste texto descrevemos a tentativa de teorização do lúdico realizada por Silva, que teria como finalidade mostrar a seriedade de um trabalho realizado nesta perspectiva. Nossa pergunta, após o que foi dito, é: perderia o ensino literário em seriedade caso trouxéssemos para ele as ferramentas do lúdico? Seria realmente complicado unir duas abordagens textuais capazes de promover o lúdico em sala de aula? Acreditamos que este texto responde negativamente a essas questões.

Quanto às propostas, além da conciliação das duas posturas diferentes, mas não excludentes, frente ao texto literário; apontamos, ainda, a possibilidade de se trabalhar com a produção escrita de forma lúdica; finalmente, deixamos em aberto a proposta do trabalho com a paródia. Consideramos que se trata de um recurso promissor, tanto por caminhar na direção do lúdico quanto por se apresentar como uma resposta crítica e ao mesmo tempo autoral ao texto literário.

\section{REFERẾNCIA BIBLIOGRÁFICA}

AMARAL, S. A correção do erro em língua estrangeira: uma abordagem pedagógica, 2011, p. 1-219 - Relatório de mestrado. FCSH, Lisboa.

GOMES, I. Sobre "por que" e "como" ensinar literatura. Nau Literária: crítica e teoria de literaturas. Porto Alegre, v. 06, n. 2, p. 1-11. Jul/dez 2010.

GONÇALVES, F. A literatura no livro didático de francês língua estrangeira. Revista virtual dos estudantes de Letras. Belo Horizonte, n. 6, p. 1-19. 2013.

JACTAT, B. Pause créative. Formation Point Didactique. Le Français dans le monde, $\mathrm{n}^{\circ}$ 358. p. 30-32. [s.d.].

HOSTIOU, Coralie. La littérature par le jeu en classe de FLE : de l'analyse théorique à la pratique, 2010, p. 1-77. - Master 2 Professionnel, Université Stendhal, Grenoble.

MUSSET, M e RÉMI, T. Quelle relation entre jeu et apprentissage à l'école? Une question renouvelée. Dossier d'actualité de la VST, n. ${ }^{\circ} 48$, p. 1-15, 2009. Disponível em http: ife.ens-lyon.fr/ife. Acesso: 25/03/2014. 
PEREIRA, J. A importância do lúdico na formação de professores em sua dimensão vivenciada. In: A importância do lúdico na formação de educadores: uma pesquisa na ação do Museu da Educação e do Brinquedo - MEB da Faculdade de Educação da USP, 2005, p.1-139 - Dissertação. Faculdade de Educação, USP.

PIETRAROIA, C. Percursos de leitura: léxico e construção de sentido na leitura em língua estrangeira. SP: Annablume, 1997.

PIETRAROIA, C. Questões de leitura: aspectos práticos e teóricos da leitura em língua estrangeira. SP: Annablume, 2001.

RIBEIRO, M. A atividade lúdica é essencial para manter o interesse do aluno: relatos de professores de língua francesa sobre o uso do lúdico em sala de aula, 2011, p.1-41 - Monografia. Departamento de Letras Estrangeiras Modernas, UFPA.

SANT’ANNA, A. R. Paródia, paráfrase e cia. São Paulo: Ática, 2003.

SANTOS, A. C. Didática da literatura no ensino de E/LE : teoria e prática. In: Anais do V Congresso Brasileiro de Hispanistas. I Congresso Internacional da Associação Brasileira de Hispanistas, Setembro/2008. Belo Horizonte, UFMG, p.1-10. Disponível em: www.letras.ufmg.br/ espanhol/Anais/index.htm. Acesso: 14/05/2014.

SÉOUD, A. L'enseignement de la littérature en classe de FLE.De l'explication de texte à la lecture. In :La place de la littérature dans l'enseignement du FLE, 2010. Actes du colloque international. Université d'Athènes. p 61-70.

SÉOUD, A. Pour une didactique de la littérature. Paris: Edition Didiers, 1997.

SILVA, H. Poétiques du jeu : la métaphore ludique dans la théorie et la critique littéraires françaises au XXe siècle -Thèse, 1999. França, Paris III. Disponível em: lewebpedagogique.com/jeulangue/mes-publications.

SILVA, H. Le jeu, un outil pédagogique à part entière pour la classe de FLE ? 2005.p. 1-7. Disponível em: lewebpedagogique.com/jeulangue/ mes-publications. Acesso: 25/03/2014.

SILVA, H. Les Jeux de société: adaptations et détournements. Cahiers de l'APLIUT, vol. XIX, nº 3, p. 14-27, 2000. Disponível em:

lewebpedagogique.com/jeulangue/mes-publications. Acesso:

$25 / 03 / 2014$ 